BIOKEMISTRI 16(2):56-63 (December 2004)

Printed in Nigeria

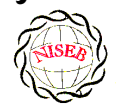

Oigerian Society for \&̊xperimental Siology

\title{
Iron chelation excludes protein synthesis inhibition in the tetracycline management of African trypanosomosis
}

\author{
Justine T. EKANEM*, Titilayo O. JOHNSON, Iyabo S. ADENIRAN and Valeelat OKEOLA
}

Department of Biochemistry, University of Ilorin, Ilorin, Nigeria.

Received 12 December 2003

MS/No BKM/2003/057, (C) 2004 Nigerian Society for Experimental Biology. All rights reserved.

\begin{abstract}
Ribonucleotide reductase, an iron requiring enzyme necessary in the production of deoxyribonucleotides required for replication in cell division and proliferation is induced during the $\mathrm{S}$ phase of the cell cycle. We have compared the trypanocidal properties of four antibiotics that show bactericidal activities by destabilizing ribosome-mRNA complex to inhibit protein synthesis. Tetracycline and oxytetracycline that have iron chelating properties extended the lifespan of trypanosome infected rats from 6 and 5 days of control to 15 and 12 days respectively while chloramphenicol and streptomycin that have no iron chelating properties could not extend the lifespan of infected rats. We confirm our earlier report that iron chelation plays a prominent role in the tetracycline management of African trypanosomosis.
\end{abstract}

Key words: Tetracycline, iron chelation, T. brucei, growth inhibition

*Author to whom all correspondence should be addressed.

E-mail: jtekanem@scientist.com , Tel: 08033880310 


\section{INTRODUCTION}

Trypanosoma brucei, the causative agent of African trypanosomosis divides and proliferates by binary fission in the process of establishing an infection in the host. Parasitaemia has been shown to correlate with the severity of the disease $^{1}$.

A major requirement of rapidly dividing cells including trypanosomes is the intracellular availability of unbound iron required by ribonucleotide reductase $\mathrm{e}^{2,3}$ in the synthesis of deoxyribonucleotides (dNTPs) from ribonucleotides (NTPs). RNR is responsible for the production of all the four dNTPs required for replication, a necessary step in cell division and proliferation $^{4-7}$. Iron chelation inhibits ribonucleotide reductase ${ }^{8-10}$. The enzyme has been suggested as an enzyme of promise for controlling African trypanosomosis ${ }^{11}$.

Ribonucleotide reductase in itself is a cell cycle dependent enzyme ${ }^{12}$. Its activity peaks at the synthetic (S) phase of the cell cycle and falls at other phases. The protein of the enzyme is synthesized from its gene by induction during the $\mathrm{S}$ phase ${ }^{12}$. Many antibiotics with bactericidal properties exert their effects by inhibiting the induction of proteins or specific enzymes from their genes ${ }^{13}$.

We have earlier reported that tetracycline $e^{14,15}$ and oxytetracycline ${ }^{16}$ can be useful in the clinical management of African trypanosomosis based on earlier reports that these antibiotics have iron chelating properties ${ }^{11}$. They are however well documented protein synthesis inhibitors that destabilize ribosome-mRNA complex during protein synthesis ${ }^{13,18}$. Other antibiotics that also destabilize the complex are chloramphenicol and streptomycin ${ }^{13,18}$. They however do not have iron chelating properties ${ }^{18}$.

In this report we have investigated the possibility of protein synthesis inhibition contributing to the possible management of African trypanosomosis by tetracycline.

\section{MATERIALS AND METHODS}

Federe strain of African trypanosomes, Trypanosoma brucei, was obtained from the
Veterinary and Livestock Studies Department, Nigeria Institute for Trypanosomiasis Research (VLS - NITR), Vom near Jos in Plateau State of Nigeria. The parasite was injected into the rats intraperitoneally and maintained by repeated passages into other rats.

\section{Antimicrobial drugs}

Four antimicrobial drugs were used to treat the experimental rats after infection. Injectable form of oxytetracycline $\mathrm{HCl}$ was a product of Haemexmedical Limited, Teviot Street, London, U.K, streptomycin sulphate B.P was a product of RIKA Pharma Gmbh, Hamburg, Germany and chloramphenicol B.P was a product of Greenfield International Ltd. London- England. Tetracycline was a product of Sigma Chemical Company, England.

\section{Inoculation of parasite}

The tail of an infected rat was cleaned with a damp cloth and tip of the tail was cut with a clean pair of scissors. Then the blood was extruded into about $0.5 \mathrm{ml}$ normal saline. The extruded blood and saline solution was swirled to mix and drawn into a $1 \mathrm{ml}$ syringe. A drop of the solution was placed on a microscope slide and observed under the light microscope to ascertain the presence of the parasite in the solution. Inoculation into the peritoneal cavity of an uninfected rat was carried out when parasite suspension contained 3 or 4 trypanosomes per view at x100 magnification.

\section{Parasite count}

Parasitaemia was determined by counting the number of trypanosomes per view under the light microscope at x100 magnification from a thin blood smear obtained from the tip of the tail of an infected rat. The Parasitaemia was recorded at 12 hour interval until the rats died.

\section{Administration of drugs}

Tetracycline, oxytetracycline- $\mathrm{HCl}$, streptomycin and chloramphenicol were all injected intraperitoneally into the animals twice daily at various concentrations as recommended by manufacturers taking the body weights of the rats into consideration. The administration 
started on the first day of sighting parasite in the blood and was continued until the rats died.

\section{Tetracycline:}

$50 \mathrm{mg}$ of tetracycline mixed with a small quantity of water was made up to $100 \mathrm{ml}$. Volumes corresponding to $10 \mathrm{mg} / \mathrm{Kg}$ rat weight were administered to the rats.

Chloramphenicol: $500 \mathrm{mg}$ of streptomycin was dissolved in $10 \mathrm{ml}$ of distilled water. Volumes corresponding to $40 \mathrm{mg} / \mathrm{kg}$ body weights were administered to the rats.

Streptomycin: $5 \mathrm{mg}$ of streptomycin was dissolved in $10 \mathrm{ml}$ of distilled water. Volumes corresponding to $15 \mathrm{mg} / \mathrm{kg}$ and $30 \mathrm{mg} / \mathrm{kg}$ body weight of the animals were administered to the rats.

Oxytetracycline-HCl: The injectable solution was obtained. The solution contained $50 \mathrm{mg}$ of oxytetracycline- $\mathrm{HCl}$ per $\mathrm{ml}$. Volumes corresponding to $40 \mathrm{mg} / \mathrm{Kg}$ body weights were administered to the rats.

Control: Control rats $(n=3)$ were infected with the parasite Trypanosoma brucei and allowed to develop without treatment. The parasitaemia was recorded until the death of the animals. Another group of three uninfected rats was also treated with the antimicrobial drugs for 21 days without infection to ascertain survival of treated animal in presence of the drugs.

\section{RESULTS}

\section{Treatment with the Drugs}

The parasitaemia of untreated rats increased infinitely and the rats died on day 5 . The uninfected rats survived the treatments for 21 days. The treatment of Trypanosoma brucei infected rats immediately parasite was first sighted in the blood with chloramphenicol is shown in Fig 1.

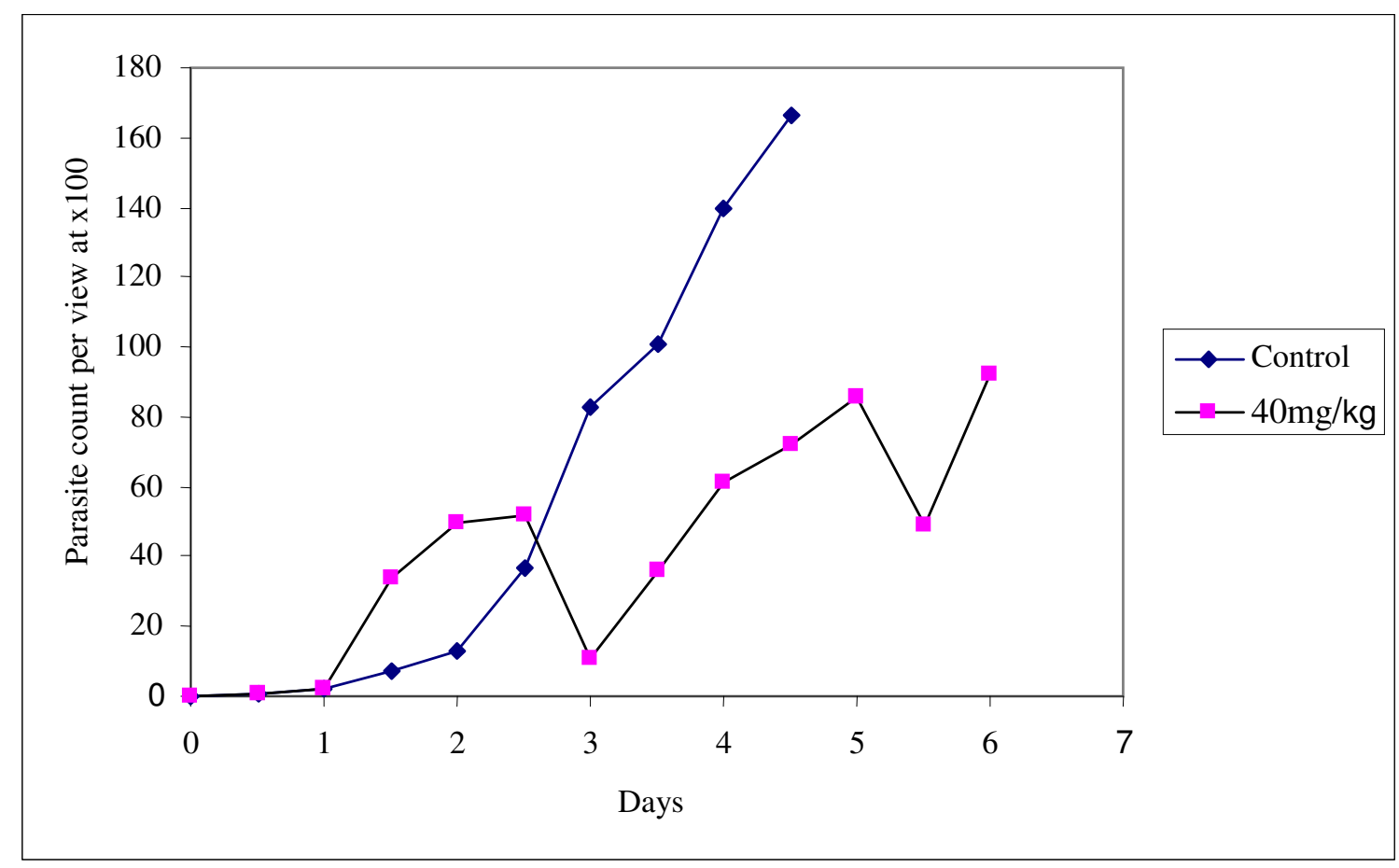

Fig 1. Treatment with Chloramphenicol. Parasiteamia of T. brucei infected rats treated twice daily with chloramphenicol as the infection progressed until death. Treatment of rats started on the day parasite was first sighted in the blood with $40 \mathrm{mg} / \mathrm{kg}$ body weight dosage of rats. Control rats were infected but not treated .The parasite count was made at 12 hour interval. Each point is an average of count from three rats. 
Chloramphenicol when administered at $40 \mathrm{mg} / \mathrm{kg}$ body weight did not extend the life span of the infected rats considerably more than the control group since the animals died on day 6 which is a day after death was recorded for the control group. A lower parasitaemia was however observed during the duration of the infection before day 6 that the animals died.

The results obtained for the treatment of infected rats when parasite was first sighted in the rats using streptomycin are shown in Fig. 2. At $15 \mathrm{mg} / \mathrm{kg}$ dosage, steady increase in parasitaemia was recorded and death ultimately on day 5 as in the control. At double the dosage, $30 \mathrm{mg} / \mathrm{Kg}$ body weight, there was steady increase in parasitaemia until day 4 when the rats died. Thus, there was no extension in the life span of the animals beyond that of the control. Parasitaemia was generally lower than those of the control in both cases.

Oxytetracycline- $\mathrm{HCl}$ extended the lifespan from 5 to 12 days as seen in Fig. 3 and tetracycline did not only extend the lifespan to 15 days but also cleared parasitaemia by the $13^{\text {th }}$ day (Fig. 4).

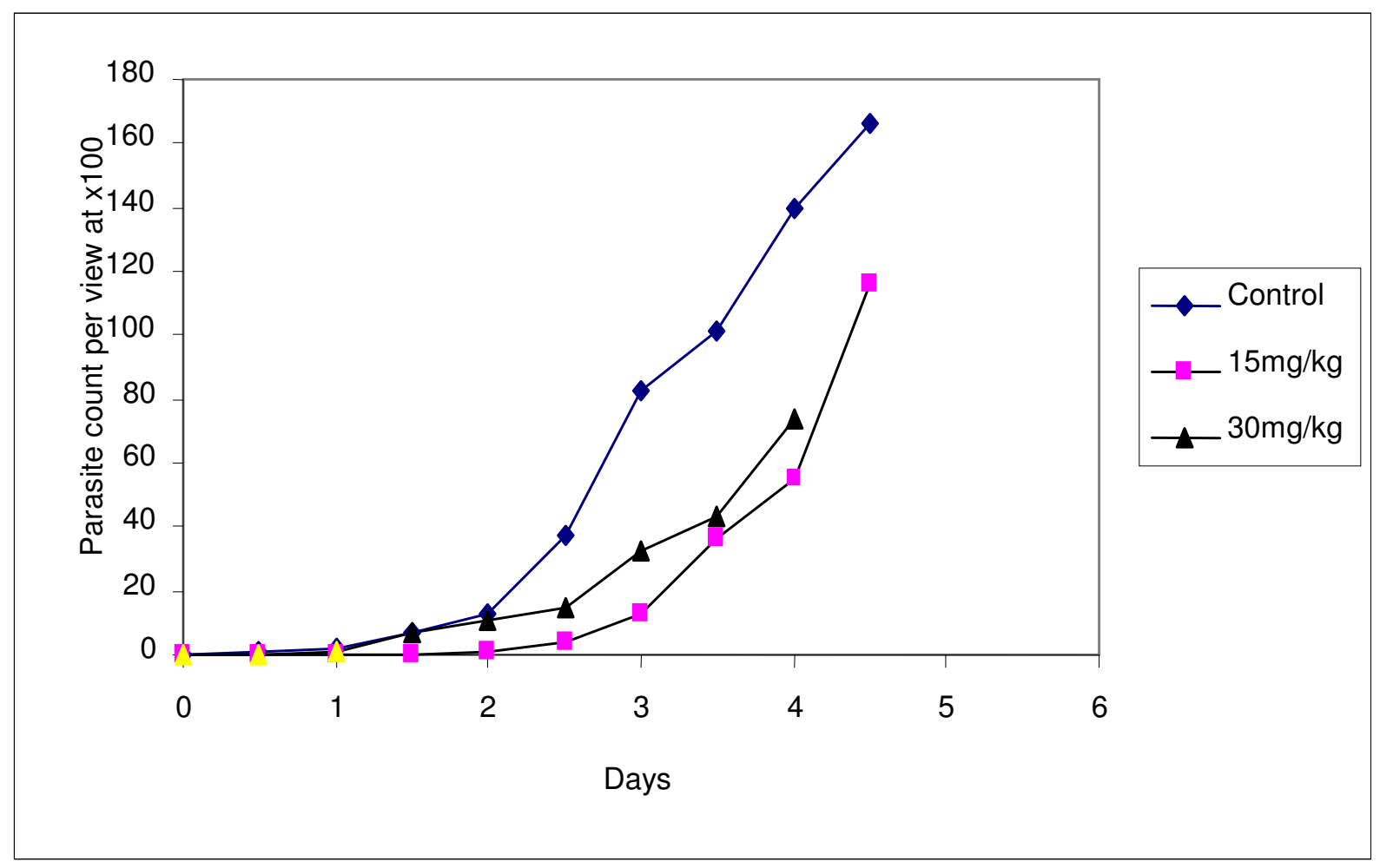

Fig 2. Treatment with streptomycin. Parasitaemia of T. brucei infected rats treated with Streptomycin twice daily as the infection progressed until death. Treatment of rats started on the day parasite was first sighted in the blood with $15 \mathrm{mg} / \mathrm{Kg}$ and $30 \mathrm{mg} / \mathrm{Kg}$ body weight of rats. Control rats were infected but not treated. The parasite count was made at 12-hour interval. Each point is an average of count from three rats. 


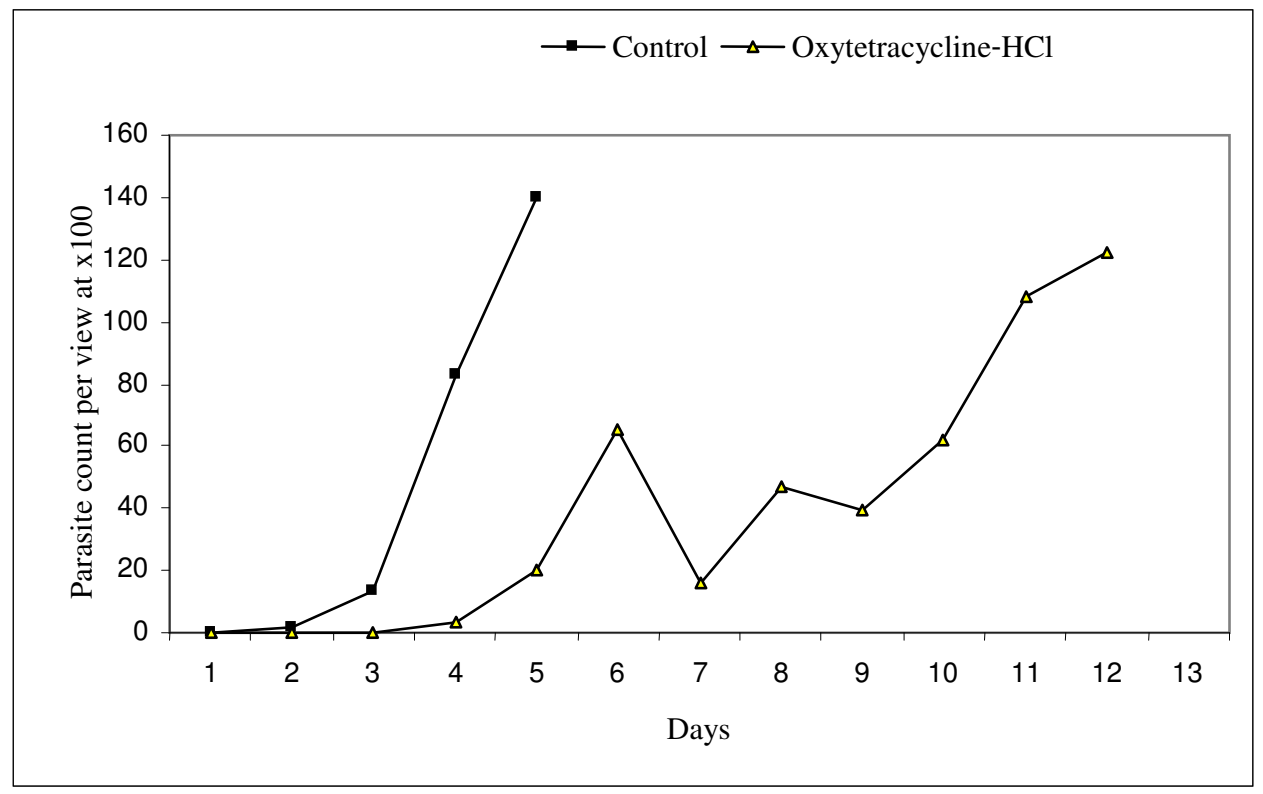

Fig 3. Treatment with oxytetracycline-HCl. Parasitaemia of T. brucei infected rats treated with oxytetracycline- $\mathrm{HCl}$ twice daily as the infection progressed until death. Treatment of rats started on the day parasite was first sighted in the blood with $40 \mathrm{mg} / \mathrm{Kg}$ body weight of rats. Control rats were infected but not treated. The parasite count was made at 12-hour interval. Each point is an average of count from three rats.

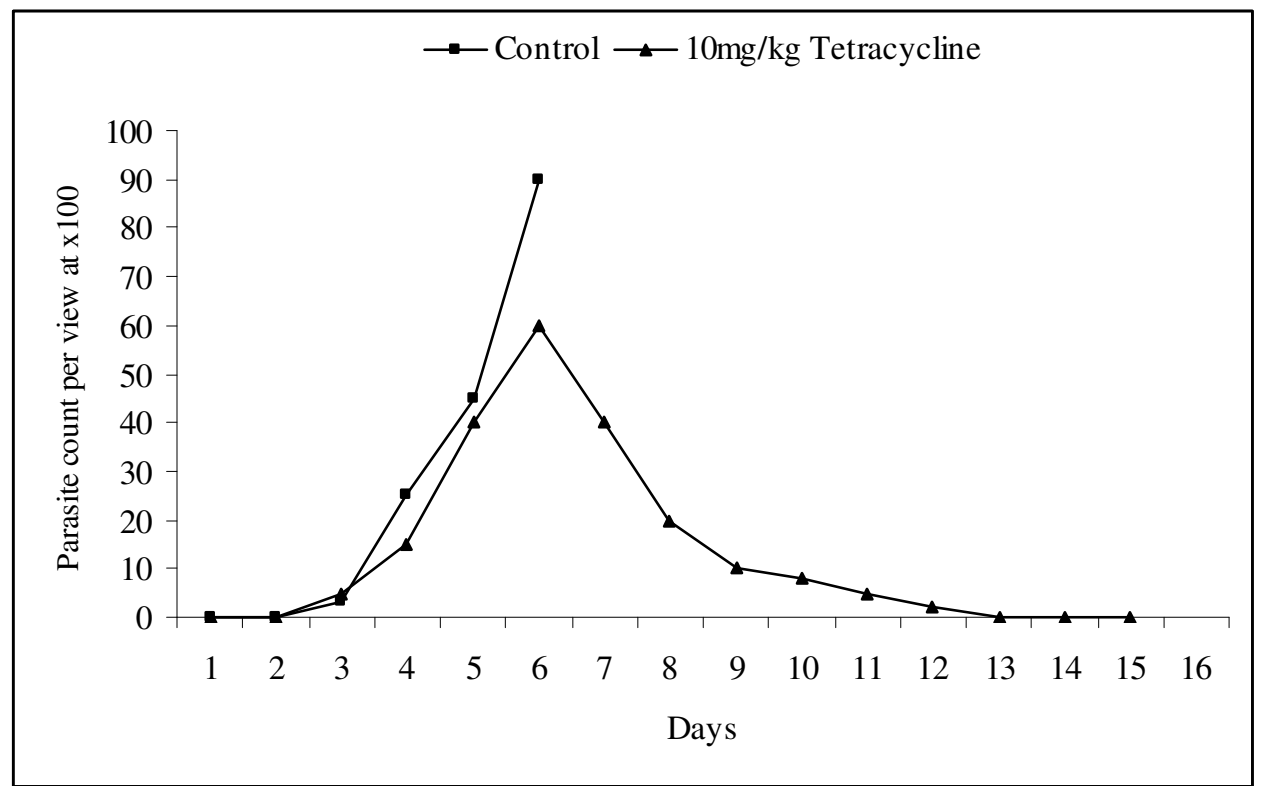

Fig 4. Treatment with tetracycline. Parasitaemia of T. brucei infected rats treated with tetracycline twice daily as the infection progressed until death. Treatment of rats started on the day parasite was first sighted in the blood with $10 \mathrm{mg} / \mathrm{Kg}$ body weight of rats. Control rats were infected but not treated. The parasite count was made at 12-hour interval. Each point is an average of count from three rats. 


\section{DISCUSSION AND CONCLUSION}

On invasion of a mammalian system, trypanosomes proliferate rapidly through binary cell division to establish its population in the infected host ${ }^{19}$. Toxins are released into the mammalian system by the trypanosomes ${ }^{20}$ and this eventually kills their host. Generally, trypanosomosis lowers the resistance of infected host to other diseases and worse still, it leads to sub-optimal immune responses after vaccination $^{21,22}$.

Iron plays a pivotal role in the synthesis of DNA in trypanosomal system through the enzyme ribonucleotide reductase ${ }^{23,24}$. If a biological system is starved of iron, the enzyme ribonucleotide reductase becomes inactivated ${ }^{25}$ ${ }^{27}$. Previous studies have revealed that growth of cells even those of trypanosomes can be successfully inhibited by depriving the cells of iron $^{27}$. Consequently, iron-chelation has thus been adopted as an attractive and possible strategy for new anti-parasite drugs and treatment of sleeping sickness ${ }^{11,28}$. Ribonucleotide reductase is a cell cycle induced enzyme $^{12}$ that is equally dependent on continuous availability of recyclable iron $^{2}$.

The antibiotics used in this study are all established protein synthesis inhibitors and in addition tetracycline and oxytetracycline are reported iron chelators ${ }^{17}$ that we have earlier reported as possible candidates for clinical management of African trypanosomosis ${ }^{14-15}$. Chloramphenicol and streptomycin do not chelate iron ${ }^{18}$.

Chloramphenicol and streptomycin have been shown in this study to be ineffective against the protozoan parasite Trypanosoma brucei (Figs. 1 and 2). Their ineffectiveness could be attributed to their inability to chelate iron. In fact, chloramphenicol has an untoward effect of increasing serum iron $^{29}$. Tetracycline and oxytetracycline notably extended the lifespan of T. brucei infected rats (Figs 3 and 4).
The results suggest that protein synthesis inhibition contributes minimally to reduction in parasitaemia observed at the early stages of infection and do not play a part in the extension of the lifespan of infected rats as observed in the treatment with the tetracycline group. We confirm our earlier result that iron chelation plays a prominent role in the suggested tetracycline management of African sleeping sickness.

\section{REFERENCES}

1. Murray, M., Morrison, W. Y. and WhiteKiv, D. V. (1988) Host susceptibility to African trypanosomosis, trypanotolerance: Adv. Parasitol. 21:52-57.

2. Thelander, L., Graslund, A. and Thelander (1983) Continual presence of oxygen and iron required for mammalian ribonucleotide reduction: Possible regulation mechanisms. Biochem. Biophys. Res. Comm. 110:859-865.

3. Stubbe J. (2003) Di-iron tyrosyl radical ribonucleotide reductases. Curr. Op. Chem. Biol. 7:183-188

4. Reichard P. (1998) Interactions between deoxyribonucleotide and DNA synthesis. Ann. Rev. Biochem. 57:349-374

5. Chabes A. and Thelander L. (2003) DNA building blocks at the foundation of better survival. Cell Cycle 2:172 173

6. Burton T. R., Kashour T., Wright J. A. and Amara F. M. (2003) Cellular signaling pathways affect the function of ribonucleotide reductase mRNA binding proteins: mRNA stabilization, drug resistance, and malignancy (Review). Int. J. Oncol. 22:21-31

7. Dormeyer, M., Reckenfelderbaumer, N., Ludemann, H. and Krauth-Siegel, R. L. (2001) Trypanothine dependent synthesis of Deoxyribonucleotides by Trypanosoma brucei Ribonucleotide Reductase. J. Biol. Chem. 276:10602-10606.

8. Cooper, C. E., Lynagh, G. R., Hoyes, K. P., Hider, R. C., Cammack, R. and 
Porter, J. B. (1996). The relationship of intracellular iron chelation to the inhibition and regeneration of human ribonucleotide reductase. J. Biol. Chem. 271:20291-20299.

9. Nyholm, S., Mann, G. J., Johannaon, a. G., Bergerson, R. J. Graslund, A. and Thelander, L. (1993) Role of ribonucleotide reductase in inhibition of mammalian all growth by potent iron chelators. J. Biol Chem. 268: 26200-26205

10. Romeo, A. M., Christen, L., Niles, E. G. and Kosman, D. J. (2001) Intracellular chelation of iron by Bipyridyl inhibits DNA virus replication - Ribonucleotide reductase maturation as a probe of intracellular iron pools. J. Biol. Chem. 276:243301-24308.

11. Ekanem, J. T. (2001) Ribonucleotide reductase as target for drug discovery against African sleeping sickness. NISEB Journal 1:287-292

12. Thelander, L. and Reichand, P. (1997) Ribonucleotide reductase. Annu. Rev. biochem. 48:133-158.

13. Aharonowitz, Y. and Cohen, G. (1981) The microbial production of pharmaceuticals. Sci. Am. 245:106-118.

14. Ekanem, J. T., Johnson T. O. and Obaleye, J. A. (2002) Tetracycline: possible cheap drug in the management of African sleeping sickness. NISEB Journal 2:83-87.

15. Johnson T. O. and Ekanem J. T. (2003) Effect of tetracycline on late-stage African trypanosomiasis in rats. Biokemistri 14:5156

16. Ekanem J. T. and Adeniran I. S. (2003) Oxytetracycline in the possible management of African trypanosomosis. Biokemistri 15:67-75

17. Grenier, D., Huot, M. and Mayrand, D. (2000) Iron- chelating activity of Teracyclines and its impact on the susceptivility of Actinobacillus antinomycetemcomitans to these Antibiotics. Antimicrob. Agents Chemother. 44:763-766

18. Sande, M. A. and Mandell, G. L. (1980) Antimicrobial agents: The aminoglycosdides, Tetracyclines and Chloramphenicol. In Goodman and Gilman, S. The Pharmacological basis of therapeutics, $6^{\text {th }}$ edition. Macmillan Publishing Co., Inc., New York.

19. Vickerman, K. (1985) Developmental cycles and Biology of pathogenic trypanosomes. Brit Med. Bull. 4:105-144.

20. Ekanem, J. T., Akanji, M. A. and Odutuga, A. A. (1996) Extracellualr proteins of Trypanosoma brucei origin lyse erythrocytes of rats in vitro. Biokemistri. 6:21-29.

21. Twinamasiko, E. K. and Kakaire, D. W. (1994) The impact of the antibody response to rinderpest vaccination under field conditions. Bull. Anim. Hlth. Prod. Afri. 42.

22. Okuna, N. (2001) African animal trypanosomosis: Nagana pp. 90-97. In J.K. Mukiibi (ed) Livestock Disease and Pest. Agriculture in Uganda, Vol. iv. National Agricultural Research Organisation. Fountain Publishers/CTA/NARD.

23. Hofer, A., Schmidt, P. P., Graslund, A. and Thelander, L. (1997) Cloning and Characterization of the R1 and R2 subunits of ribonucleotide reductase from Trypanosoma brucei. Proc. Natl. Acad. Sci. USA. 94:6959-6964.

24. Hofer, A. Ekanem, J. T. and Thelander, L. (1998) The Allosteric regulation of Trypanosoma brucei Ribonucleotide reductase studied in vitro and in vivo J. Biol. Chem. 273:34098-34104.

25. Chabes, A., Domkin, V., Larsson, G., Liu, A., Grashund, A., Wijmenga, S. and Thelander, L. (2000) Yeast ribonucleotide reductase has heterodimeric iron-radical containing subunit. Proct. Nat. Acad. Sci., USA. 97:2447-2479.

26. Chitamber, C. R., Wereley, J. P., Herman, T., Antholine, W. E. and O'Brien, W. J. (2000) Cellular adaptation of down-regulated iron transport into lymphoid leukaemia cells: effects on the expression of the gene for ribonucleotide reductase. Biochem. J. 345:681-685. 
27. Fast, B. Kremp, K., Boshart, M. and Steverding, D. (1999) Iron-dependent regulation of transferring receptor expression in Trypanosoma brucei. Biochem. J. 342:691-696.

28. Breidbach, T., Scory, S., KrauthSiegel,R.L. and Steverding, D. (2002) Growth inhibition of bloodstream forms of Trypanosoma brucei by the iron chelator deferoxamine. Int. J. of Parasitology. 32:473-479.

29. Aiello, S. E., and Mays, A., (1998) The Merck Veterinary Manual, 8th ed. Merck \& Co. Inc. Whitehouse Station, N. J. USA. 